\title{
Characterization of the products obtained from alkaline conversion of tuff and metakaolin
}

\author{
Agnieszka Grela ${ }^{1} \cdot$ Michał Łach $^{2} \cdot$ Tomasz Bajda $^{3} \cdot J$ anusz Mikuła ${ }^{2} \cdot$ Marek Hebda $^{2}$
}

Received: 14 August 2017 / Accepted: 5 January 2018/Published online: 23 January 2018

(C) The Author(s) 2018. This article is an open access publication

\begin{abstract}
Currently, there has been a growing interest of zeolite materials for industrial and scientific purpose. Synthetic zeolites are more often used than natural ones due to its higher purity and more uniform particle sizes. Numerous investigations are conducted in searching of inexpensive raw materials suitable for zeolite synthesis. Moreover, the temperature, pressure, times and $\mathrm{SiO}_{2} / \mathrm{Al}_{2} \mathrm{O}_{3}$ ratio are the most important parameters which play key roles in the synthesis processes. Due to such a large number of factors that affect the process, zeolite synthesis has been undergoing constant development. Nowadays, researchers focus on the methods of synthesizing zeolites at ambient temperature and pressure. Metakaolin and tuff are natural raw materials which can be turned into a brand new class of synthetic zeolites. However, each requires different method of synthesis in order to obtain a material with best physical properties. This paper discusses the process of alkaline activation of synthetic zeolites from natural raw materials: volcanic tuff excavated in Filipowice and metakaolin obtained from Rominco company. Two methods: fusion and low-temperature synthesis, were used in the presented research. Moreover, the physical properties of raw materials and zeolites obtained were shown. Based on the XRD analysis, it was verified that materials after the synthesis process contained zeolites A, Na-X and faujasite-Na. Furthermore, the dehydration and thermal decomposition phenomena of the tuff and metakaolin before and after the synthesis process were determined by coupled TG/MS techniques.
\end{abstract}

Keywords Zeolite synthesis $\cdot$ Zeolite Na-X $\cdot$ Faujasite $\cdot$ Coupled techniques $\cdot$ TG/MS

\section{Introduction}

Zeolite synthesis is a complex physicochemical process because during crystallization, many phenomena may simultaneously take place, for example polymerization, precipitation from the solution, nucleation and other process typical of colloidal aqueous solutions. Zeolite synthesis is usually conducted in hydrothermal conditions in an alkaline environment (e.g., $\mathrm{NaOH}$ solution). Zeolites

Marek Hebda

mhebda@pk.edu.pl

1 Institute of Water Engineering and Management, Cracow University of Technology, Kraków, Poland

2 Institute of Materials Engineering, Cracow University of Technology, Kraków, Poland

3 Department of Geology, Geophysics and Environmental Protection, AGH University of Science and Technology, Kraków, Poland can be successfully obtained from different natural raw materials [1-4]. Moreover, various manufacturing and agro wastes have been studied as a starting material in synthesizing zeolite [5-8]. The chemical composition of the raw material used, particularly the presence of silicon and aluminum oxides, is one of the important factors responsible for obtaining various types of zeolites [9]. Moreover, the temperature, pressure, times and $\mathrm{SiO}_{2} / \mathrm{Al}_{2} \mathrm{O}_{3}$ ratio are crucial parameters which play key roles in the synthesis processes. For instance, synthesis of faujasite is possible with different parameters [10-15].

Two contradictory explanations are available for the mechanism of zeolite synthesis: (1) the transformation of amorphous gel into crystalline zeolite during solid phase and (2) nucleation and crystallization from solution. The process of zeolite structures formation is possible through: (1) the formation of skeleton made of oxides (primarily the aluminosilicate oxides) or (2) the formation of cations or extra-skeletal particles [16]. Due to such a large number of 
Table 1 Chemical composition of tuff and metakaolin

\begin{tabular}{llllllllll}
\hline Material & \multicolumn{2}{l}{ Oxide composition/mass\% } \\
\cline { 2 - 9 } & $\mathrm{SiO}_{2}$ & $\mathrm{TiO}_{2}$ & $\mathrm{Fe}_{2} \mathrm{O}_{3}$ & $\mathrm{Al}_{2} \mathrm{O}_{3}$ & $\mathrm{CaO}$ & $\mathrm{MgO}$ & $\mathrm{K}_{2} \mathrm{O}$ & $\mathrm{Na}_{2} \mathrm{O}$ & Other \\
\hline Tuff & 56.04 & 0.85 & 5.38 & 16.73 & 5.39 & 0.60 & 9.16 & 0.39 & 5.46 \\
Metakaolin & 53.01 & 0.74 & 1.34 & 41.54 & 0.27 & 0.38 & 0.71 & 0.82 & 1.19 \\
\hline
\end{tabular}

factors that affect the process, zeolite synthesis has been undergoing constant development. Nowadays, researchers focus on the methods of synthesizing zeolites at ambient temperature and pressure [17].

Zeolites obtain their physical properties from their specific structure, that is, their aluminosilicate skeleton structure, which is porous and contains a network of irregular chambers and channels of various dimensions and shapes [18-21]. The most common properties of zeolites are in the range: density, $2.1-2.3 \mathrm{~g} \mathrm{~cm}^{-3}$; specific surface area, $\quad 200-900 \mathrm{~m}^{2} \mathrm{~g}^{-1}$; ion exchange capacity, 150-700 meq $100 \mathrm{~g}^{-1}$; water adsorption capacity, $1-25 \%$ by weight; and thermal stability, $500-1000{ }^{\circ} \mathrm{C}[22,23]$.

Currently, there has been a growing interest in the application of zeolite materials in processes such as selective absorption, reversible water absorption and dehydration, molecular separation, catalysis and ion exchange.

Zeolites are more and more frequently investigated by thermal analysis methods. By means of thermal analysis, one not only can assess the quality and purity of the examined material, but also can carry out research on the polymorphism of specific substances and establish how various additives affect the physical and chemical properties of the zeolites obtained [24, 25]. Analysis of thermal decomposition effects is so important, because thermal stability of zeolites is considered to be a crucial factor which decides the use of zeolites in industries, especially when specific zeolites are intended to be used as catalysts or sorbents.

This paper discusses the opportunity to cheaply synthesize zeolites from inexpensive raw materials, which occur in large quantities and are easily available. The presented results focuses on the process of alkaline activation and synthesis of zeolites from two natural resources: (1) tuff excavated in Filipowice and (2) metakaolin obtained from Rominco company. The properties of the products obtained were investigated by XRD, SEM, BET and coupled thermal analysis techniques.

\section{Materials and methods}

\section{Characteristics of source materials}

The metakaolin used in this research was delivered by Rominco company. It was obtained after dehydration process carried out at $700-800{ }^{\circ} \mathrm{C}$ from pure kaolin of Chinese origin. Their oxide composition is presented in Table 1. The tuff was excavated in Filipowice, a small village near Kraków (southern Poland). It consists of sanidine, kaolinite, biotite, illite, quartz, highly modified feldspars, pieces of other rocks, opaque minerals, microcrystalline binder and carbonate binder. Tuff is a highly porous rock with chaotically distributed amorphous crystals of biotite.

\section{Process of synthesis}

Zeolites were synthesized by means of two methods: (1) fusion method $(\mathrm{F})$ and (2) low-temperature method (L).

\section{Fusion method}

Specific amounts of raw material (S), tuff and metakaolin, and activator $(\mathrm{NaOH}$ whose purity $>98 \%$, produced by PCC Rokita SE) were mixed in a fireproof crucible. The capacity of the crucible was $0.1 \mathrm{dm}^{3}$. Then, the mixture was sintered at $550{ }^{\circ} \mathrm{C}$ for $4 \mathrm{~h}$ in a muffle furnace in the presence of air. The material obtained was ground and put in a glass vessel $\left(1 \mathrm{dm}^{3}\right.$ vol.) Then, $0.045 \mathrm{dm}^{3}$ of water per $1 \mathrm{~g}$ of sintered material was added and the vessel content was mixed for $1 \mathrm{~h}$ by ultrasound. Next, the vessel was put in laboratory dryer. Initially, it was dried for $24 \mathrm{~h}$ at $100{ }^{\circ} \mathrm{C}$ (activation) and then for $24 \mathrm{~h}$ at $60{ }^{\circ} \mathrm{C}$ (crystallization). Finally, the samples were cooled to room temperature and filtered in order to remove the solution remaining after the activation phase. After the filtration, the samples were washed with $10 \mathrm{dm}^{3}$ of distilled water (in order to achieve a pH of about 10) and dried at $105^{\circ} \mathrm{C}$ for $6 \mathrm{~h}$.

\section{Low-temperature method}

Specific amounts of raw material (S), tuff or metakaolin, were mixed with $3 \mathrm{M}$ of $\mathrm{NaOH}$ (purity $>98 \%$ ). The proportion of the solution used was $0.1 \mathrm{dm}^{3} / 10 \mathrm{~g}$ of the raw material. They were then mixed in cylindrical polypropylene vessels $\left(1 \mathrm{dm}^{3}\right.$ volume each) and tightly closed. These vessels were left for 30 days at room temperature. The solutions were intensively mixed and shaken every day. After the formation of zeolite, the samples were filtered in order to remove the solution remaining after the activation phase. After the process of filtration, the samples were 


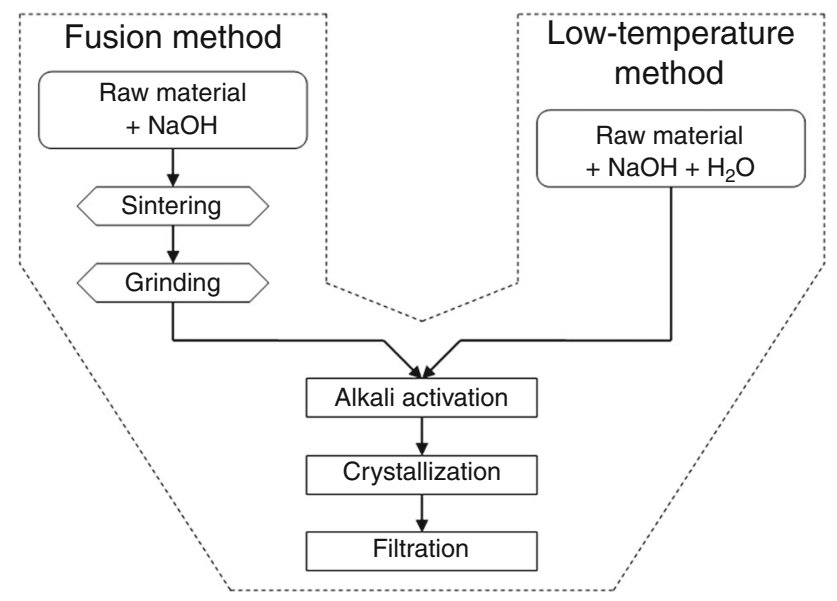

Fig. 1 Zeolite synthesis by means of fusion and low-temperature methods

Table 2 Acronyms of the materials examined

\begin{tabular}{lll}
\hline No. & Acronyms & Full name \\
\hline 1 & T & Tuff before the synthesis \\
2 & TL & Tuff after the low-temperature synthesis \\
3 & TF & Tuff after the fusion synthesis \\
4 & M & Metakaolin before the synthesis \\
5 & ML & Metakaolin after the low-temperature synthesis \\
6 & MF & Metakaolin after the fusion synthesis \\
\hline
\end{tabular}

washed with $10 \mathrm{dm}^{3}$ of distilled water (in order to achieve a $\mathrm{pH}$ of about 10). The filtration process and washing were conducted with filter paper dedicated to qualitative analysis (density $84 \mathrm{~g} \mathrm{~m}^{-2}$ ), which was made of pure cellulose and cotton linters (filtration time $=10 \mathrm{~s}$ ). Finally, the samples were dried at $105{ }^{\circ} \mathrm{C}$ for $6 \mathrm{~h}$.

Figure 1 presents the comparison of the most important stages of the fusion method and low-temperature method of zeolite synthesis. Acronyms of the materials obtained during synthesis are presented in Table 2 .

\section{Examination methods and equipments}

The tuff is basically a rock; therefore, there was a need to turn it into fine powder before the synthesis. The grinding process was carried out for $15 \mathrm{~min}$., with rotary speed 300 rev $\min ^{-1}$ in an ultra centrifugal mill RETSCH ZM1. Obtained particle size was $<0.08 \mathrm{~mm}$. Metakaolin was used in a delivery state because its particle size was less than $10 \mu \mathrm{m}$.

The mineral composition of the raw materials and the products obtained was examined by XRD powder diffraction method with a Rigaku SmartLab XRD diffractometer (copper anode, step of measurement $0.05^{\circ}$, counting time $10 \mathrm{~s})$. The main phases were identified by means of the measurement of interplanar distances and the subsequent comparison of the obtained set of data with the pattern set. Diffraction data processing was performed based on the data present in the directory ICDD (International Center for Diffraction Data 2014) and a computer program XRAYAN. Moreover, all materials were observed by scanning microscope JEOL JSM-820. Before the analysis, the powders were dried and covered with thin layers of gold with JEOL JEE-4X vacuum evaporator. The density of the materials was determined with helium pycnometer ATC. Textural characterization of the materials was carried out with a low-temperature nitrogen adsorption-desorption method. Nitrogen adsorption-desorption measurements were taken at $-196{ }^{\circ} \mathrm{C}$ using an ASAP 2020 volumetric adsorption analyzer (Micromeritics). The BET specific surface areas (SBET) of the investigated samples were evaluated using the standard Brunauer-Emmett-Teller (BET) method for nitrogen adsorption data in the range of relative pressure $\mathrm{p} / \mathrm{p}^{\circ}$ to 0.99 . The total pore volumes were estimated at a relative pressure of 0.99 . The volumes of micropores $V_{\text {tot }}^{0.99}$ (pore width of $<2 \mathrm{~nm}$ ) and $V_{\text {mik }}^{\mathrm{DR}}$ (pore width of $<2 \mathrm{~nm}$ ) were estimated according to the methodology of Dubinin-Radushkevich, whereas the volume of mesopores $V_{\text {mezo }}^{\mathrm{BJH}}$ (pore width larger than $2 \mathrm{~nm}$ and $<50 \mathrm{~nm}$ ) was estimated according to the methodology of Barrett-Joyner-Halendy (BJH).

Thermal measurements were taken with STA 409 CD (Netzsch) thermogravimetric techniques (TG) including evolved gas analysis by quadruple mass spectrometry (QMS 403/5 SKIMMER). The temperature range was from 30 to $900{ }^{\circ} \mathrm{C}$ at a heating rate of $10{ }^{\circ} \mathrm{C} \mathrm{min}^{-1}$. The samples were annealed at $900{ }^{\circ} \mathrm{C}$ for $30 \mathrm{~min}$. The on-line gas was analyzed (distance between the sample and QMS was $<20 \mathrm{~mm}$ ) by QMS with electron ionization source. The spectrometer was operated in MID (multiple ion detection) mode. Air was used as a carrier gas at a flow rate of $80 \mathrm{~mL} \mathrm{~min}^{-1}$. The QMS was checked with calcium oxalate monohydrate (Fluka). The TG/QMS data were analyzed with Proteus software (version 5.2.0) from Netzsch. All curves that are presented were corrected against empty runs.

\section{Results and discussion}

Figures 2 and 3 show the X-ray patterns of the investigated natural raw materials, tuff from Filipowice and metakaolin, respectively. On the other hand, Figs. 4 and 5 demonstrate the X-ray patterns obtained after the activation process. The mineral composition of the tuff was dominated by feldspars and muscovite. Quartz, calcite and hematite were 


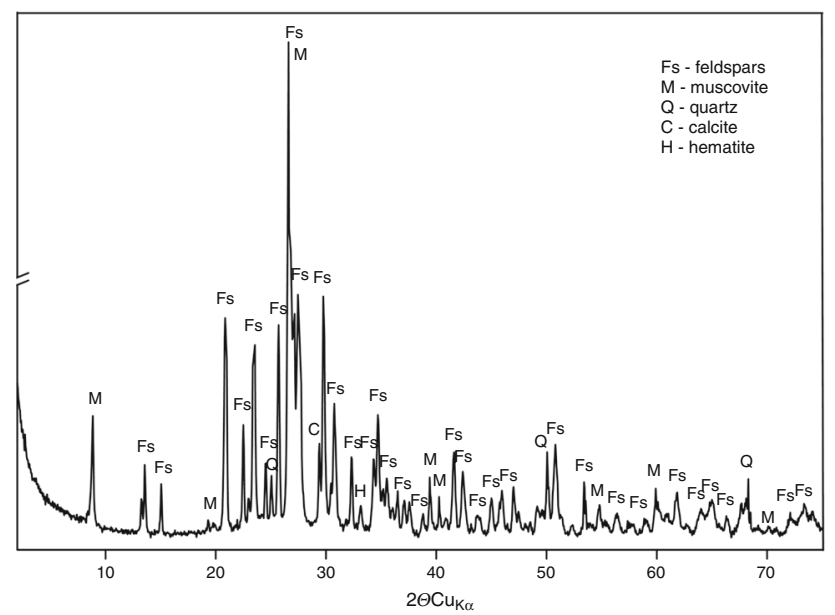

Fig. 2 XRD pattern of the tuff before synthesis (T)

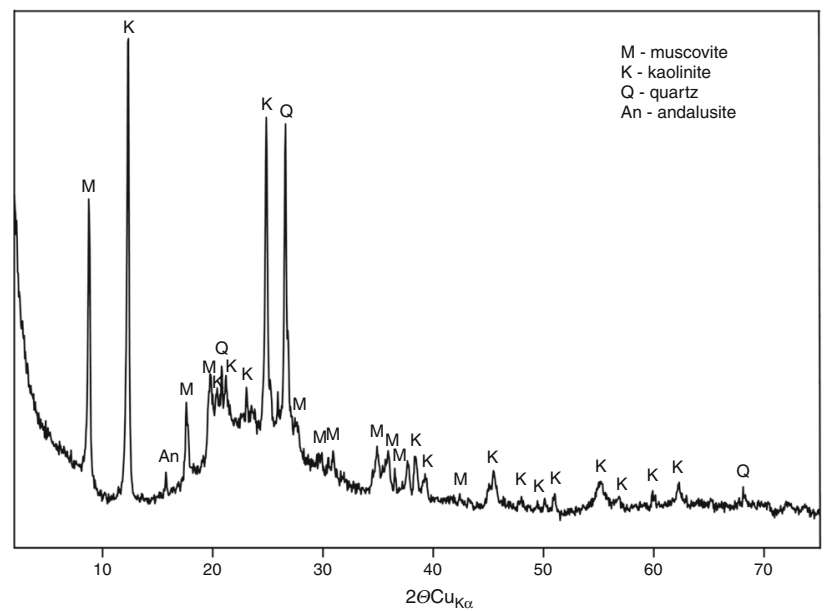

Fig. 3 XRD pattern of metakaolin before synthesis (M)

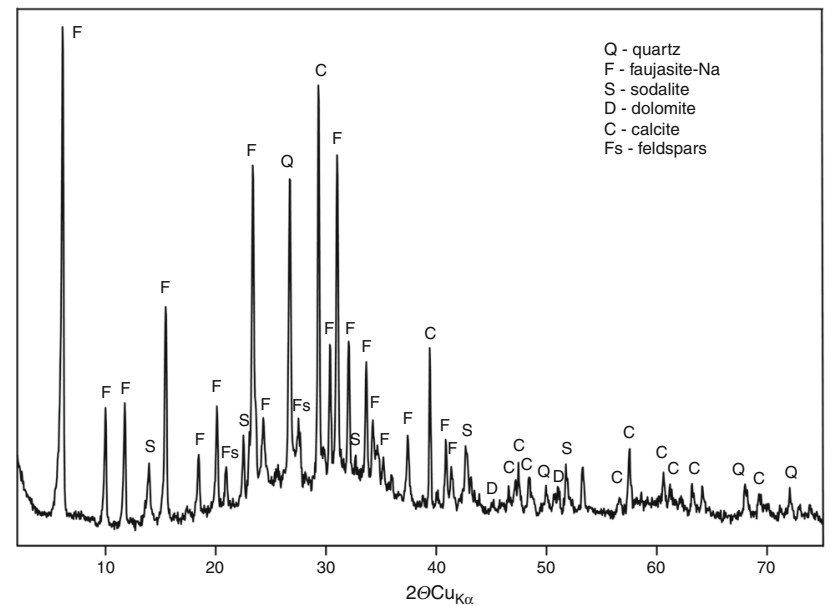

Fig. 4 XRD pattern of the tuff after fusion synthesis (TF)

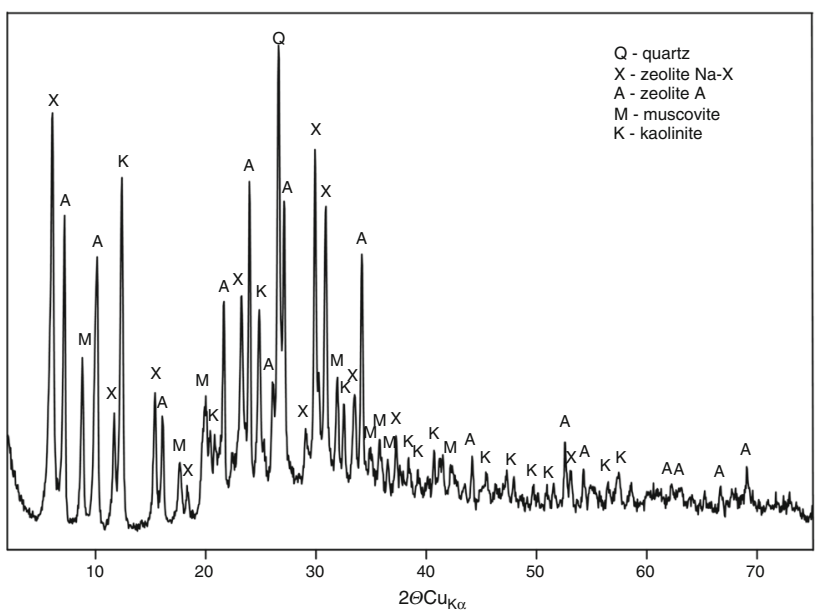

Fig. 5 XRD pattern of metakaolin after low-temperature synthesis (ML)

also found in raw material. In the case of metakaolin samples, the largest share consisted mainly of muscovite and kaolinite and the remaining minerals were quartz and andalusite. The XRD results show the influence of alkaline activation process on investigated materials. The significant rise of the background as a result of the increases in the amorphous phase was observed. The products obtained for TF sample was determined to mainly consist of faujasite-Na (Fig. 4), whereas the ML material consisted mainly of zeolite A and Na-X (Fig. 5). Similar fusion products were also obtained by other researchers [26-28].

Table 3 shows the density of the investigated materials. Before the synthesis, the density of the tuff and metakaolin was about $2.622 \mathrm{~g} \mathrm{~cm}^{-3}$. The lowest value of density, typical of zeolites, was obtained for tuff after the fusion synthesis and for metakaolin after the low-temperature synthesis: 2.213 and $2.158 \mathrm{~g} \mathrm{~cm}^{-3}$, respectively. No significant differences were found between the densities of the tuff before and after the low-temperature synthesis. There was also no significant difference between the densities of metakaolin before and after the fusion synthesis.

Figure 6 presents the morphology of the minerals used in the zeolite synthesis. It was noticed that the tuff particles

Table 3 Density of the materials examined before and after the synthesis (acronyms according to Table 2)

\begin{tabular}{lll}
\hline No. & Acronym & Density $/ \mathrm{g} \mathrm{cm}^{-3}$ \\
\hline 1 & T & $2.622 \pm 0.001$ \\
2 & TL & $2.564 \pm 0.002$ \\
3 & TF & $2.213 \pm 0.002$ \\
4 & M & $2.624 \pm 0.002$ \\
5 & ML & $2.158 \pm 0.002$ \\
6 & MF & $2.365 \pm 0.005$ \\
\hline
\end{tabular}



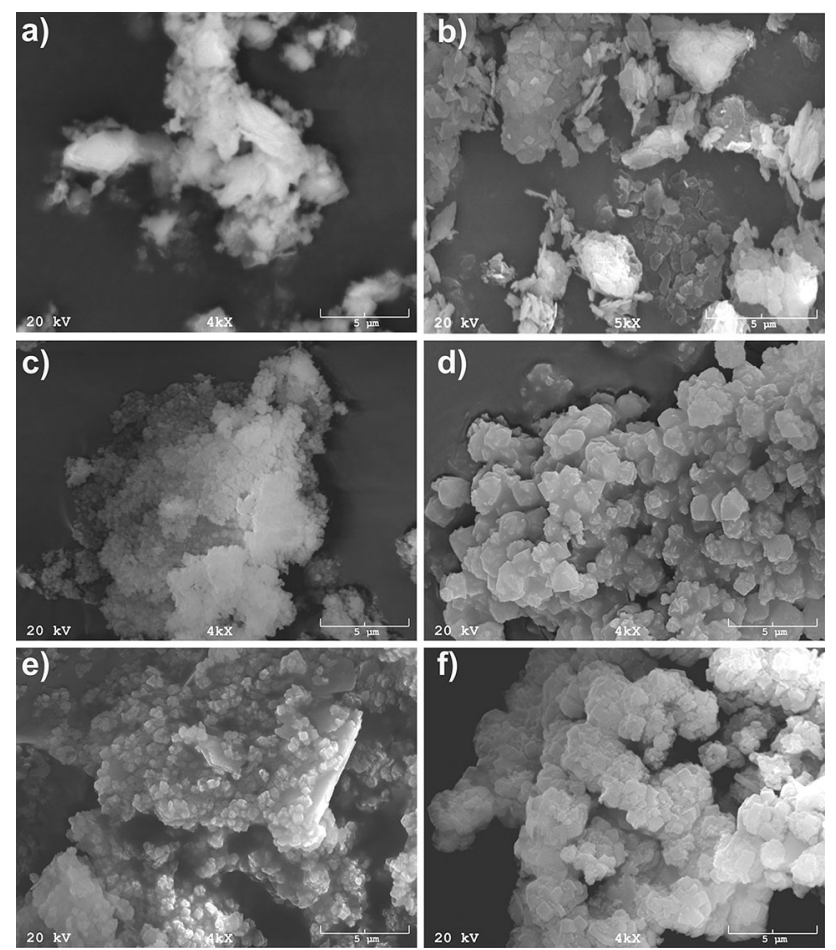

Fig. 6 SEM images of: a the tuff before the synthesis (T); b metakaolin before the synthesis (M); c tuff after the lowtemperature synthesis (TL); d tuff after the fusion synthesis (TF); e metakaolin after the low-temperature synthesis (ML); f metakaolin after the fusion synthesis (MF)

agglomerated very often (Fig. 6a). Moreover, in general, the tuff particles are irregular in shape and tiny in size, whereas metakaolin particles are plate-like in shape and occur both individually and as agglomerates. The size of a single metakaolin particle hardly exceeds $10 \mu \mathrm{m}$. The edges of the particles can be either sharp or rounded. No spherical particles were detected in the above-mentioned substrates for the zeolite synthesis.

Figure $6 \mathrm{c}-\mathrm{f}$ presents the microstructures of the synthesized tuff and metakaolin. Regarding the tuff (TF), the isometrical and octahedral structures are the prevailing ones. Metakaolin crystals synthesized by low-temperature method (ML) are aggregates of irregular shape, usually plate-like or scale-like. Similar observations have been described by Youssef et al. [29] and Rios et al. [30]. The morphology of the tuff obtained after low-temperature synthesis (TL) and metakaolin after fusion synthesis (MF) significantly differed from that of TF and ML. For these samples, TL and MF, only few crystallites were detected and the amorphous phases were prevailing.

The broad hysteresis loops of adsorption-desorption isotherms for the tuff before the synthesis were noticed (T; Fig. 7), which proves the presence of well-developed mesoporous texture. The mesoporous texture of the tuff (T) used for the synthesis unequivocally demonstrates that the pores have a low specific surface area and small capacity (Table 4). The course of BET adsorption-desorption isotherm for metakaolin before the synthesis $(\mathrm{M}$; Fig. 7) was different. The adsorption isotherms for the tuff after the fusion synthesis (TF; Fig. 7b) and for metakaolin after low-temperature synthesis (ML; Fig. 7c) demonstrated that the lower values of relative pressure are accompanied by an increase in the adsorption values. This might be due to the direct effect of significantly increased number of micropores, which is one of the features typical of zeolite minerals.

The isotherm of sample T corresponds to type III/IV, which indicates a high share of macropores and mesopores. Isotherm of sample TL (Fig. 7a) corresponds to type IV classification, which indicates the presence of mesopores in the shape of narrow slits. According to the IUPAC classification, isotherm of TF sample (Fig. 7b) at lower concentrations has a shape similar to that of type I isotherms, which indicates the presence of micropores. At higher concentrations, the shape of the curve corresponds to type IV isotherm. Isotherm of sample M corresponds to type III/ IV (Fig. 7c, d), while isotherm of sample ML as well as MF to type IV.

Table 4 presents the results of the porosimetry examination of the referred materials. The value of the specific surface area for the raw materials is not high and amounts to about 6.8 and $13.6 \mathrm{~m}^{2} \mathrm{~g}^{-1}$ for tuff (T) and metakaolin (M), respectively. Tuff obtained after low-temperature synthesis (TL) and metakaolin after fusion synthesis (MF) show only slight increase in BET parameter. On the other hand, the specific surface areas of the tuff obtained after fusion synthesis (TF) and that of metakaolin after lowtemperature synthesis (ML) achieved the highest values 327.0 and $328.2 \mathrm{~m}^{2} \mathrm{~g}^{-1}$, respectively. Moreover, based on the data presented in Table 4, it was found that in the raw materials analyzed, mesopores were found to be in a dominant share (51-56\%). Macropores also had a significant share (32-41\%). Analysis of textural parameters of materials after synthesis showed changes in the pore. The fusion method, for tuff, showed an increased share of micropores by $38 \%$ and a decreased share of mesopores by $13 \%$. In the case of metakaolin, low-temperature synthesis showed an increased share of micropores by $57 \%$ and a decreased share of mesopores by $25 \%$.

Figure $8 \mathrm{a}, \mathrm{b}$ presents the loss on ignition during the examination. The tuff and metakaolin before the synthesis showed a little loss in weight compared to the products obtained after synthesis (Fig. 8a, b, Table 5). This might be due to the level of hydration. It is higher for the materials after synthesis, because water present in zeolites is crucial for the stabilization of their porous texture. The crystalline structure of zeolites (Fig. 6c-f) allows them to store water of nearly $21 \%$ of their overall mass. When exposed to 
(a)

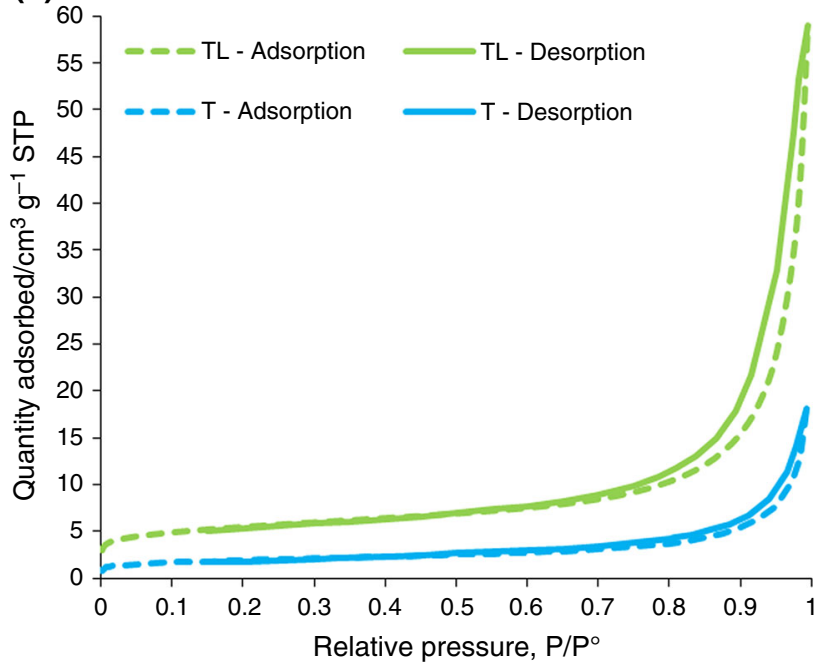

(c)

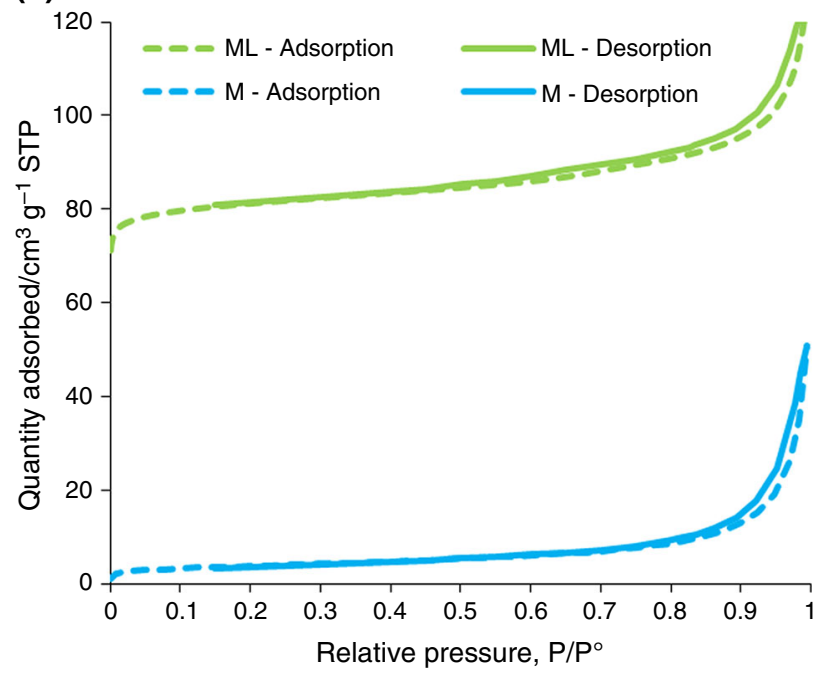

Fig. 7 Adsorption-desorption isotherms of $\mathrm{N}_{2}$ : a for the tuff before (T) and after fusion synthesis (TF); $\mathbf{b}$ for the tuff before (T) and after low-temperature synthesis (TL); $\mathbf{c}$ for metakaolin before (M) and after

elevated temperatures, both natural and synthetic zeolites release steam of water, but this is not detrimental of their mineral structure. The dehydration of the tuff after the fusion synthesis (TF) takes place at about $200{ }^{\circ} \mathrm{C}$, and the subsequent loss of $\mathrm{H}_{2} \mathrm{O}$ amounts to $15.4 \%$. Comparison of the tuff obtained before and after the low-temperature (b)

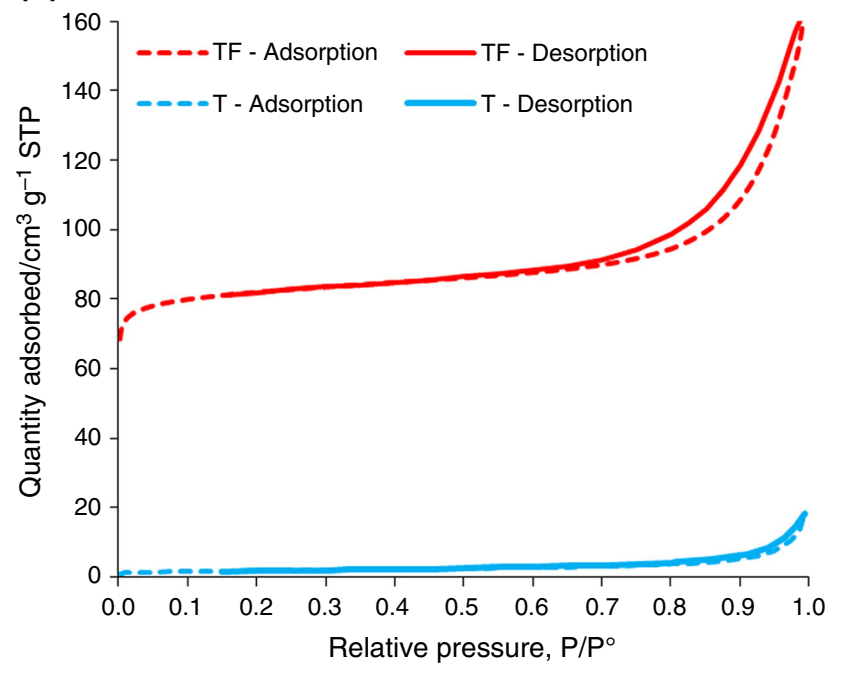

(d)

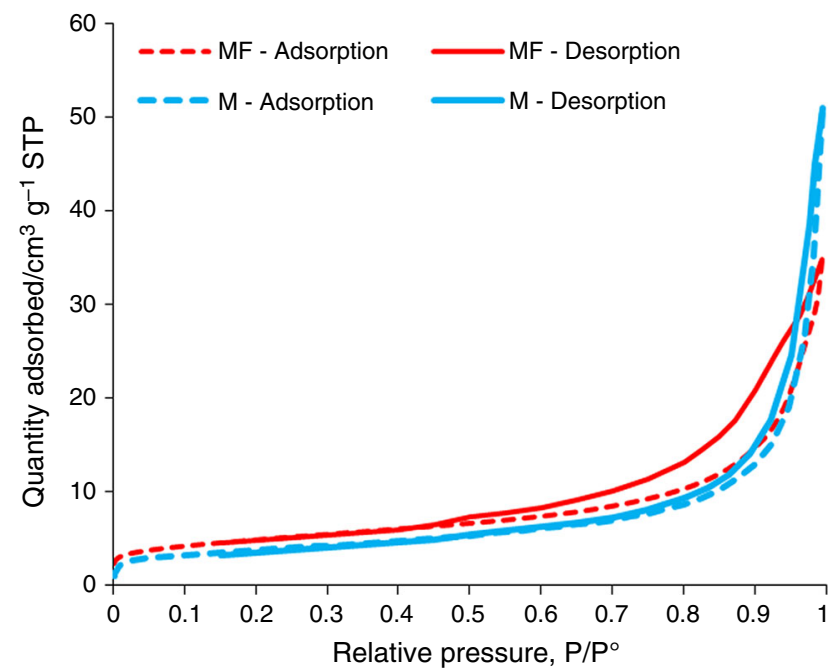

fusion synthesis (MF); $\mathbf{d}$ for metakaolin before (M) and after lowtemperature synthesis (ML)

synthesis showed that such method did not significantly alter its thermal properties. The TG curve of the metakaolin obtained after the fusion method (MF) showed that the properties of metakaolin were halfway between the properties of the raw material and the product obtained by lowtemperature metakaolin synthesis. Moreover, metakaolin
Table 4 Textural properties of materials examined before and after the synthesis (acronyms according to Table 2)

\begin{tabular}{llclll}
\hline No. & Acronym & Specific surface area BET $/ \mathrm{m}^{2} \mathrm{~g}^{-1}$ & $V_{\text {tot }}^{0.99} / \mathrm{cm}^{3} \mathrm{~g}^{-1}$ & $V_{\mathrm{mik}}^{\mathrm{DR} /} \mathrm{cm}^{3} \mathrm{~g}^{-1}$ & $V_{\text {mezo }}^{\mathrm{BJH} /} \mathrm{cm}^{3} \mathrm{~g}^{-1}$ \\
\hline 1 & $\mathrm{~T}$ & 6.8 & 0.025 & 0.003 & 0.014 \\
2 & $\mathrm{TF}$ & 327.0 & 0.246 & 0.123 & 0.105 \\
3 & $\mathrm{TL}$ & 19.7 & 0.080 & 0.007 & 0.043 \\
4 & $\mathrm{M}$ & 13.6 & 0.069 & 0.006 & 0.035 \\
5 & $\mathrm{MF}$ & 17.2 & 0.049 & 0.006 & 0.036 \\
6 & $\mathrm{ML}$ & 328.2 & 0.187 & 0.123 & 0.049 \\
\hline
\end{tabular}



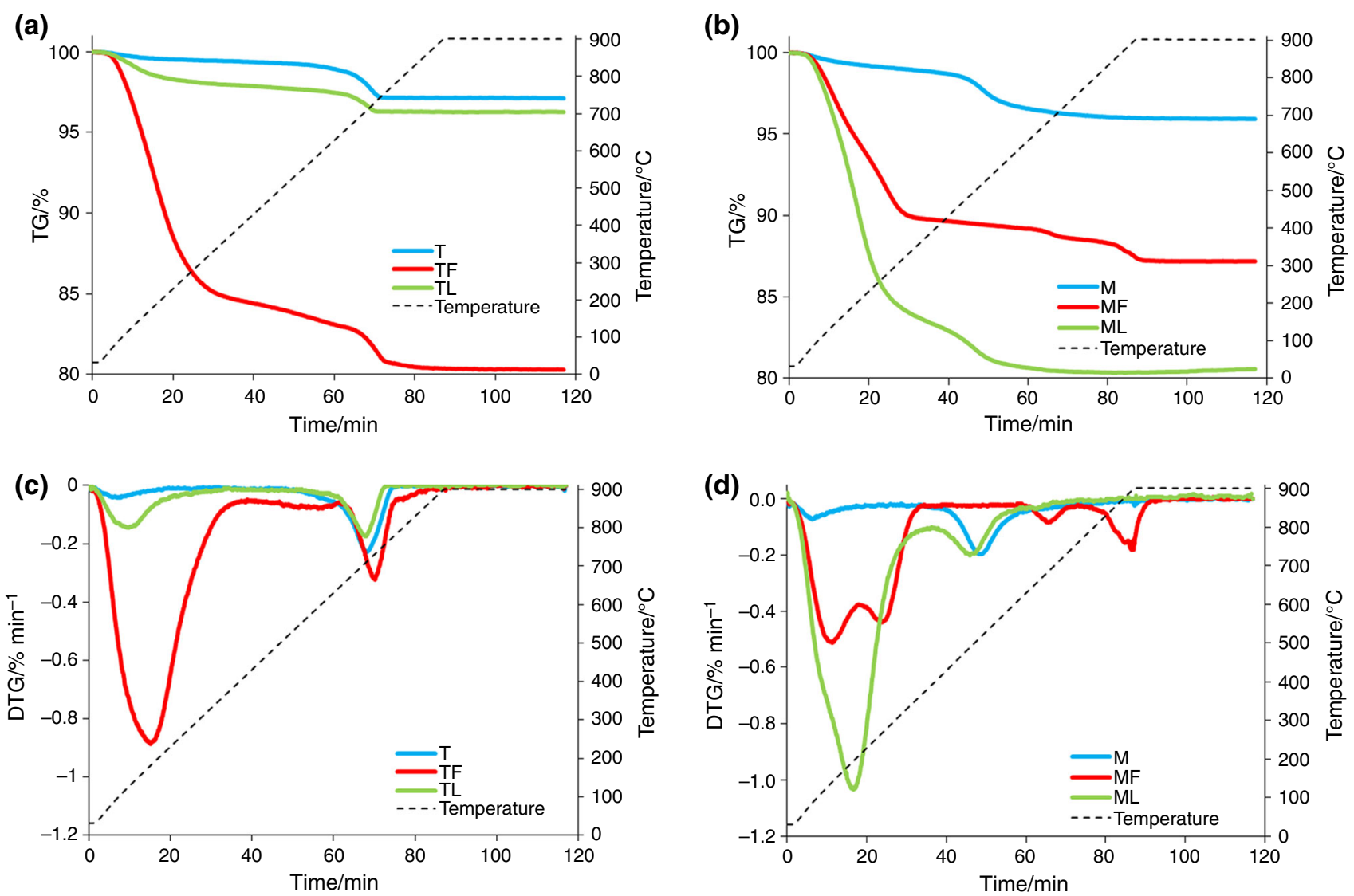

Fig. 8 TG (a, b) and DTG (c, d) curves of the investigated materials (acronyms according to Table 2)

Table 5 Evolution of mass changes along with temperature ranges of the materials analyzed

\begin{tabular}{|c|c|c|c|c|c|c|c|c|c|c|c|c|}
\hline \multirow[t]{2}{*}{ Notation } & \multicolumn{3}{|l|}{1 Step } & \multicolumn{3}{|c|}{2 Steps } & \multicolumn{3}{|c|}{3 Steps } & \multicolumn{3}{|l|}{4 Steps } \\
\hline & $\begin{array}{l}\text { Onset/ } \\
{ }^{\circ} \mathrm{C}\end{array}$ & $\begin{array}{l}\text { Endset/ } \\
{ }^{\circ} \mathrm{C}\end{array}$ & $\begin{array}{l}\text { Mass } \\
\text { changes/\% }\end{array}$ & $\begin{array}{l}\text { Onset/ } \\
{ }^{\circ} \mathrm{C}\end{array}$ & $\begin{array}{l}\text { Endset/ } \\
{ }^{\circ} \mathrm{C}\end{array}$ & $\begin{array}{l}\text { Mass } \\
\text { changes/\% }\end{array}$ & $\begin{array}{l}\text { Onset/ } \\
{ }^{\circ} \mathrm{C}\end{array}$ & $\begin{array}{l}\text { Endset/ } \\
{ }^{\circ} \mathrm{C}\end{array}$ & $\begin{array}{l}\text { Mass } \\
\text { changes/\% }\end{array}$ & $\begin{array}{l}\text { Onset/ } \\
{ }^{\circ} \mathrm{C}\end{array}$ & $\begin{array}{l}\text { Endset/ } \\
{ }^{\circ} \mathrm{C}\end{array}$ & $\begin{array}{l}\text { Mass } \\
\text { changes/\% }\end{array}$ \\
\hline $\mathrm{T}$ & 30.0 & 209.2 & -0.4 & 209.2 & 526.4 & -0.3 & 526.4 & 755.1 & -2.1 & - & - & - \\
\hline TL & 30.0 & 298.5 & -1.9 & 298.5 & 616.3 & -0.6 & 616.3 & 742.2 & -1.3 & - & - & - \\
\hline TF & 30.0 & 385.7 & -15.4 & 385.7 & 664.3 & -1.6 & 664.3 & 783.1 & -2.3 & 783.1 & 900.0 & -0.4 \\
\hline M & 30.0 & 451.0 & -1.4 & 451.0 & 619.0 & -2.0 & 619.0 & 900.0 & -0.6 & - & - & - \\
\hline ML & 30.0 & 297.8 & -15.4 & 297.8 & 435.6 & -2.0 & 435.6 & 533.4 & -1.4 & 533.4 & 900.0 & -0.6 \\
\hline MF & 30.0 & 342.6 & -10.1 & 342.6 & 652.2 & -0.8 & 652.2 & 716.1 & -0.4 & 716.1 & 900.0 & -1.5 \\
\hline
\end{tabular}

obtained by the fusion method (MF) was the only material in which dehydration process by a two-stage loss in weight was determined at a temperature up to $342.6^{\circ} \mathrm{C}$. The DTG curve peaks were determined at about 200 and $280{ }^{\circ} \mathrm{C}$ with a corresponding mass loss of $10.1 \%$ (Fig. 8b, d, Table 5). The highest values of loss on ignition for the tuff samples (Fig. 8a, Table 6) were obtained by fusion synthesis, whereas that for the metakaolin samples were obtained by low-temperature synthesis (Fig. 8b, Table 6). It was determined that the total value of the loss on ignition for these both materials was similar (about 19.5\%; Table 6).
Table 6 Loss on ignition of the examined materials

\begin{tabular}{llc}
\hline No. & Acronym & Loss on ignition/\% \\
\hline 1 & T & -2.8 \\
2 & TL & -3.8 \\
3 & TF & -19.7 \\
4 & M & -4.0 \\
5 & ML & -19.4 \\
6 & MF & -12.8 \\
\hline
\end{tabular}


(a)

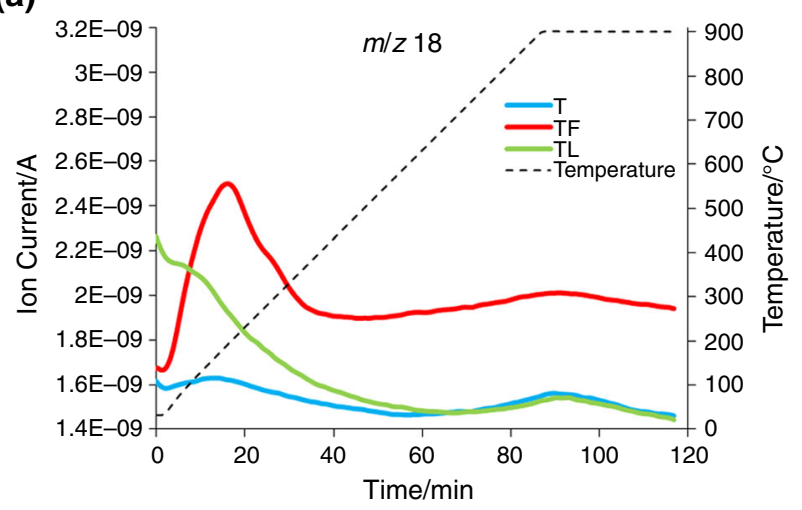

(c)

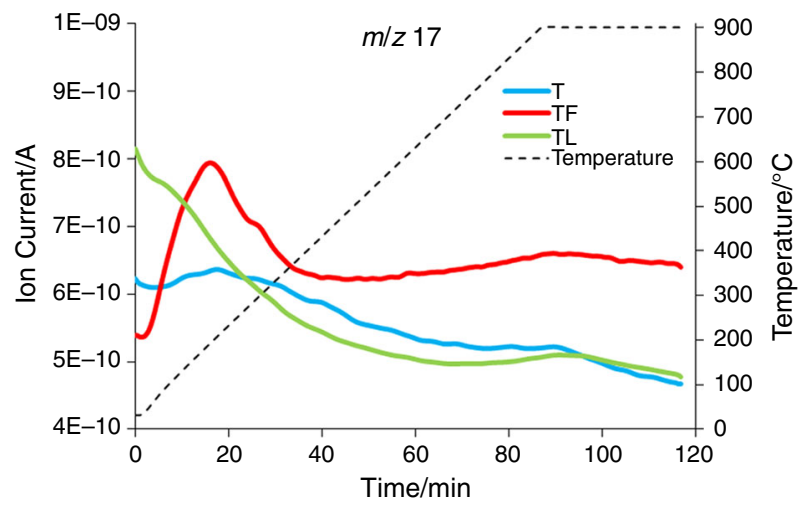

(e)

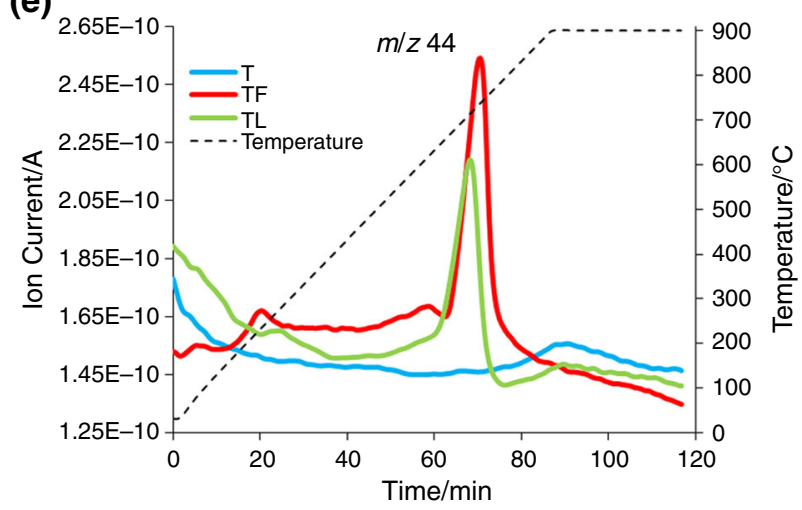

(g)

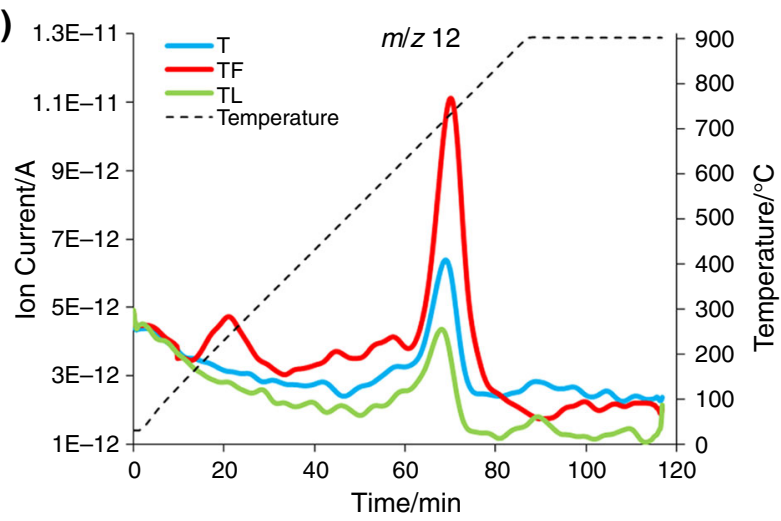

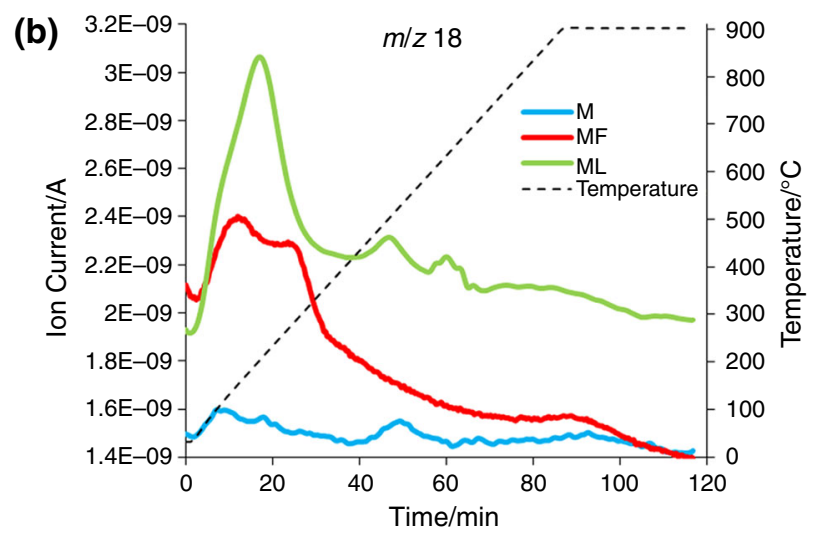

(d) $\left.{ }^{1 E-09}\right] \quad m / z 17$
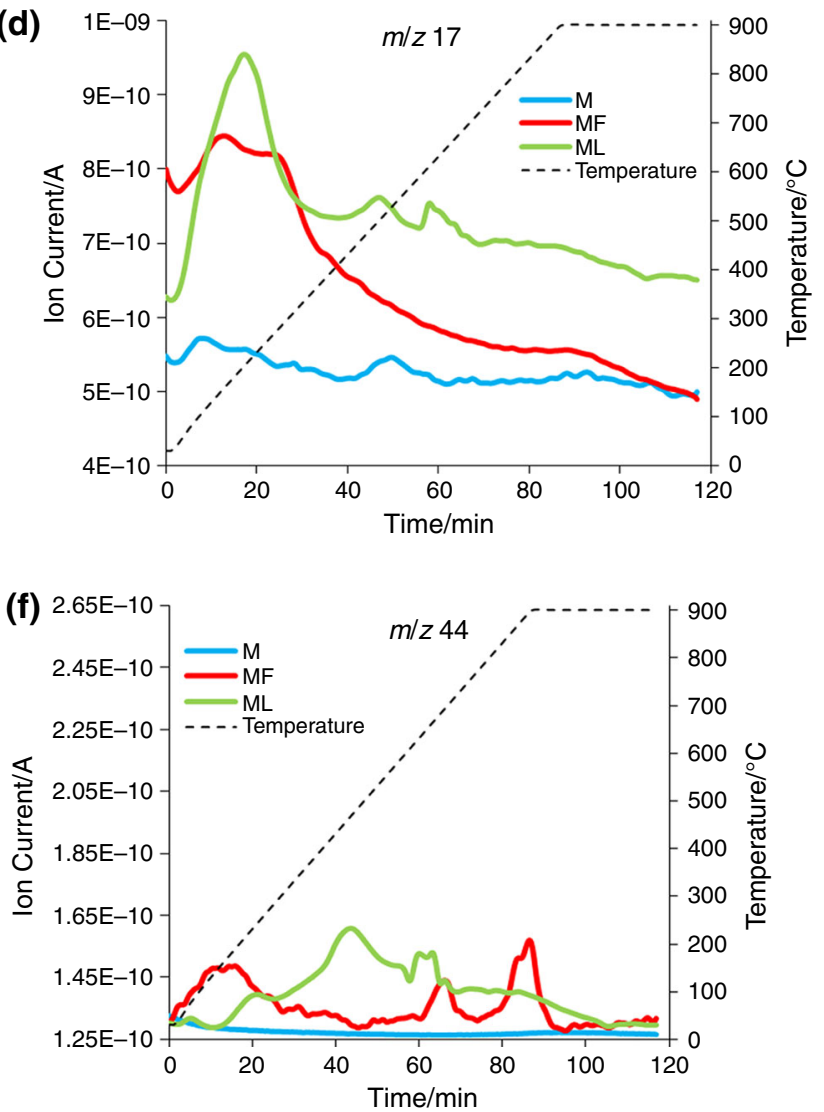

(h)

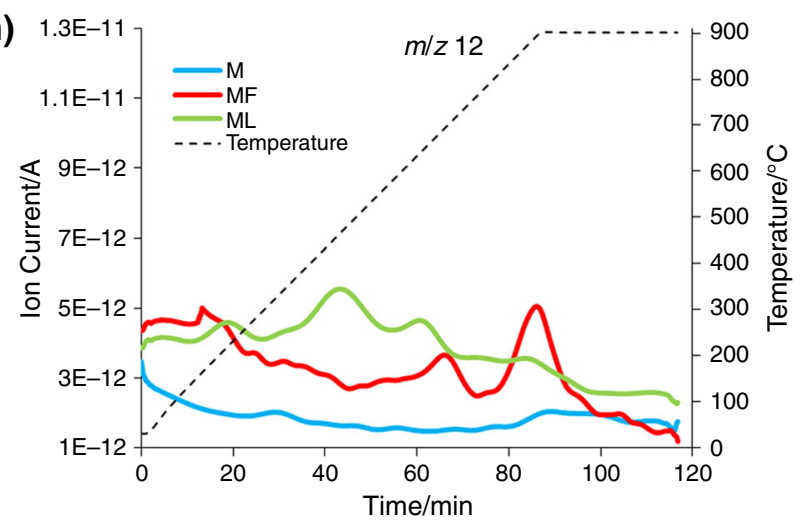

Fig. 9 Mass spectra obtained via MID mode of the investigated materials (acronyms according to Table 2) 
Furthermore, the presence of evaporating water was determined during the analysis of gas products released from zeolites during the TG examination $(\mathrm{m} / \mathrm{z}, 17$ and $\mathrm{m} /$ $z$ 18; Fig. 9a-d). The strongest atomic mass spectra of water were identified in the samples of tuff which underwent fusion synthesis and in the samples of metakaolin after low-temperature synthesis. This result was in a full agreement with the results of the TG examination (Fig. 8a, b).

In case of tuff, the next significant loss in weight (about $2 \%$ ) was observed at a temperature range between 526 and $783{ }^{\circ} \mathrm{C}$ (Fig. 8a, c, Table 5). This effect was the same for the raw material as well as tuff-derived synthetic zeolite. Therefore, this phenomenon is related to the thermal decomposition of the tuff. This mass loss is accompanied by the strong release of carbon dioxide $(\mathrm{m} / \mathrm{z} 44)$ and carbon $(m / z, 12)$ (Fig. 9e, g).

It was also observed that mass changes very similar to the above-mentioned ones occur in kaolin-derived zeolite materials. However, they generally begin at a temperature of about $100{ }^{\circ} \mathrm{C}$ lower compared to tuff (Fig. 8a, b). These effects are accompanied by the release of gas products, carbon dioxide $-m / z, 44$ and carbon-m/z 12 (Fig. 9f, h). However, the intensity of carbon dioxide and carbon release is much lower than in the case of tuff.

\section{Conclusions}

On the basis of the results obtained from the research, it can be stated that the zeolites from the tuff should be synthesized by fusion method, whereas the zeolites from metakaolin should be synthesized by low-temperature method. Moreover, by means of the TG/QMS coupled analysis it was proved that thermal stability of the samples strictly depends on their type. The recorded thermal analysis results demonstrate the direct relationship between the used method of synthesis, the chemical reactions and physical processes taking place in the examined materials. Zeolites $\mathrm{Na}-\mathrm{X}$ and A obtained from metakaolin as well as faujasite-Na achieved from tuff were characterized by a specific surface area around $328 \mathrm{~m}^{2} \mathrm{~g}^{-1}$ and density $2.1 \mathrm{~g} \mathrm{~cm}^{-3}$. Furthermore, the coupled thermal analysis TG/ MS allowed to describe the processes of dehydration and decomposition of zeolite materials.

Open Access This article is distributed under the terms of the Creative Commons Attribution 4.0 International License (http://creative commons.org/licenses/by/4.0/), which permits unrestricted use, distribution, and reproduction in any medium, provided you give appropriate credit to the original author(s) and the source, provide a link to the Creative Commons license, and indicate if changes were made.

\section{References}

1. Burriesci N, Crisfulli ML. Hydrothermal synthesis of zeolites from low-cost natural silica-alumina sources. Zeolites. 1984;4:384-8.

2. Ma Y, Yan Ch, Alshameri A, Qiu X, Zhou Ch, Li D. Synthesis and characterization of $13 \mathrm{X}$ zeolite from low-grade natural kaolin. Adv Powder Technol. 2014;25(2):495-9.

3. Lee J, Han S, Hyeon T. Synthesis of new nanoporous carbon materials using nanostructured silica materials as templates. J Mater Chem. 2004;14:478-86.

4. Yaghi OM, O'Keeffe M, Ockwig NW, Chae HK, Eddaoudi M, Kim J. Reticular synthesis and the design of new materials. Nature. 2003;423:705-14.

5. Prasetyoko D, Ramli Z, Endud S, Hamdan H, Sulikowski B. Conversion of rice husk ash to zeolite beta. Waste Manage. 2006;26:1173-9.

6. Tanaka H, Fujii A. Effect of stirring on the dissolution of coal fly ash and synthesis of pure-form Na-A and-X zeolites by two-step process. Adv Powder Technol. 2009;20:473-9.

7. Grela A, Hebda M, Łach M, Mikula J. Thermal behavior and physical characteristics of synthetic zeolite from CFB-coal fly ash. Microporous Mesoporous Mater. 2016;220:155-62.

8. Moisés MP, da Silva CTP, Meneguin JG, Girotto EM, Radovanovic E. Synthesis of zeolite $\mathrm{NaA}$ from sugarcane bagasse ash. Mater Lett. 2013;108:243-6.

9. Novembre D, Di Sabatino B, Gimeno D, Pace C. Synthesis and characterization of $\mathrm{Na}-\mathrm{X}$, Na-A and Na-P zeolites and hydroxysodalite from metakaolinite. Clay Miner. 2011;46:339-54.

10. Gross-Lorgouilloux M, Soulard M, Caullet P, Patarin J, Moleiro E, Saude I. Conversion of coal fly ashes into faujasite under soft temperature and pressure conditions: influence of additional silica. Microporous Mesoporous Mater. 2010;127:41-9.

11. Fotovat F, Kazemian H, Kazemini M. Synthesis of Na-A and faujasitic zeolites from high silicon fly Ash. Mater Res Bull. 2009;44:913-7.

12. Gross M, Soulard M, Caullet P, Patarin J, Saude I. Synthesis of faujasite from coal fly ashes under smooth temperature and pressure conditions: a cost saving process. Microporous Mesoporous Mater. 2007;104:67-76.

13. Thiago F, Heloise Ch, Pastore O, Cardoso D. A simple synthesis procedure to prepare nanosized faujasite crystals. Microporous Mesoporous Mater. 2012;161:67-75.

14. Martens JA, Grobet PJ, Jacobs PA. The chemistry of the dealumination of faujasite zeolites with silicon tetrachloride. Stud Surf Sci Catal. 1991;63:355-65.

15. Chen HY, Wydra J, Zhang XY, Lee PS, Wang ZP, Fan W, Tsapatsis M. Hydrothermal synthesis of zeolites with three-dimensionally ordered mesoporous-imprinted structure. J Am Chem Soc. 2011;133(32):12390-3.

16. Talanova VN, Lependina OL, Buyanovskaya AG, Dzvonkovskii SL. Determination of silicon and aluminum oxides in zeolites. Inorg Mater. 2011;47(14):1548-50.

17. Gualtieri AF. Syntesis of sodium zeolites from a natural halloysite. Phys Chem Mater. 2001;28:719-28.

18. Robson H. Verified syntheses of zeolitic materials. Amsterdam: Elsevier; 2001.

19. Aiello R, Giordano G, Testa F. Impact of zeolites and other porous materials on the new technologies at the beginning of the new millennium, vol. 142. Amsterdam: Elsevier; 2002.

20. Guisnet M, Gilson JP. Zeolites for cleaner technologies. London: Imperial College Press; 2002.

21. Campos VP, Buchler M. Anionic sorption onto modified natural zeolites using chemical activation. Environ Geol. 2007;52:1187-92. 
22. Armbruster T, Gunter ME. Crystal structures of natural zeolites. In: Bish DL, Ming DW, editors. Natural zeolites: occurrence, properties, applications. Rev. Mineral Geochem. 2001;45:1-67.

23. Szala B, Bajda T, Matusik J, Zięba K, Kijak B. BTX sorption on Na-P1 organo-zeolite as a process controlled by the amount of adsorbed HDTMA. Microporous Mesoporous Mater. 2015;202:115-23.

24. Park M, Choi LCh, Lim WT, Kim MCh, Choi J, Heo NH. Molten-salt method for the synthesis of zeolitic materials: II. Characterization of zeolitic maerials. Microporous Mesoporous Mater. 2000;37:91-8.

25. Grela A, Łach M, Mikula J, Hebda M. Thermal analysis of the products of alkali activation of fly ash from CFB boilers. J Therm Anal Calorim. 2016;124(3):1609-21.
26. Heller-Kallai L, Lapides I. Reactions of kaolinites and metakaolinites with $\mathrm{NaOH}$-comparison of different samples (Part 1). Appl Clay Sci. 2007;35:99-107.

27. Chandrasekhar S, Pramada PN. Microwave assisted synthesis of zeolite A from metakaolin. Microporous Mesoporous Mater. 2008;108:152-61.

28. Mackinnon IDR, Millar GJ, Stolz W. Hydrothermal syntheses of zeolite N from kaolin. Appl Clay Sci. 2012;58:1-7.

29. Youssef H, Ibrahim D, Komarneni S. Microwave-assisted versus conventional synthesis of zeolite A from metakaolinite. Microporous Mesoporous Mater. 2008;115:527-34.

30. Ríos CA, Williams CD, Fullen MA. Nucleation and growth history of zeolite LTA synthesized from kaolinite by two different methods. Appl Clay Sci. 2009;42:446-54. 